\begin{tabular}{|l|l|}
\hline $\begin{array}{c}\text { European Association for the } \\
\text { Development of Renewable Energies, Environment } \\
\text { and Power Quality (EA4EPQ) }\end{array}$ & $\begin{array}{l}\text { International Conference on Renewable Energies and Power Quality } \\
\text { (ICREPQ'12) } \\
\text { Santiago de Compostela (Spain), 28th to 30th March, 2012 }\end{array}$ \\
\hline
\end{tabular}

\title{
Two Control Strategies for Aggregated Wind Turbine Model with Permanent Magnet Synchronous Generator
}

\author{
M. J. Mercado-Vargas ${ }^{\mathrm{a}}$, Fujin Deng ${ }^{\mathrm{b}}$, O. Rabaza ${ }^{\mathrm{a}}$, E. Alameda-Hernandez ${ }^{\mathrm{a}}$, Zhe Chen ${ }^{\mathrm{b}}$ \\ ${ }^{\text {a }}$ Section of Electrical Engineering. Department of Civil Engineering \\ Granada University \\ Campus of Fuente Nueva, 18071, Granada, Spain \\ Phone: +34 958241001 (ext. 2448), e-mail: mjmercado@ugr.es, ealameda@ugr.es, ovidio@ugr.es \\ ${ }^{\mathrm{b}}$ Department of Energy Technology \\ Aalborg University \\ Pontoppidanstræde 101, 9220, Aalborg, Denmark \\ Phone: +45 533381 84, email: fde@et.aau.dk, zch@et.aau.dk
}

\begin{abstract}
The behaviour of an aggregated wind turbine model with permanent magnet synchronous generator is studied when a wind fluctuation or a grid disturbance happens. Two control strategies are used for the generator-side converter and they are also used to evaluate the low-voltage ride-through capability of the aggregated model. MATLAB/Simulink has been used for the simulations and the results show that the proposed aggregated model behaviour follows closely the detailed one and, therefore, it is a good way to represent the wind turbine reaction.
\end{abstract}

\section{Key words}

Aggregated model, permanent magnet synchronous generator, rotor speed control, active power control, lowvoltage ride-through capability.

\section{Introduction}

Wind energy penetration in power systems is growing day by day. In former times, when the amount of wind generation was very small compared to other energy output technologies, network operator conditions usually required wind farms to disconnect under any disturbances to avoid damages to the grid. Nowadays, as wind energy penetration in power systems has increased, it is really important that wind generation continues to operate during grid disturbances, and usually the network operator wants to predict the behaviour of power grids with a large presence of wind farms.

Complete wind farm models represent the reaction of wind turbines to grid disturbances and wind fluctuations. However, as the size of wind farms keep increasing, it is not practical to simulate the entire wind farm by representing each individual turbine. To simplify and reduce calculation time, it is common to represent the whole wind farm by groups of turbines or by one single equivalent turbine.
The aggregated wind farm models with variable speed wind turbines have not been studied for a long time, and most of the investigations are focused on doubled fed induction generators (DFIG) [1], [2].

However, due to the attractive characteristics of the variable speed wind turbine with permanent magnet synchronous generator (PMSG) versus other configurations [3], the need to study the aggregated models with PMSG based wind turbines has arisen [4].

In this paper, the variable-speed wind turbines with the detailed model and the aggregated model are introduced. Two control strategies including speed control and power control are respectively used for the aggregated wind turbine model so as to evaluate its performance under the wind fluctuation and grid disturbance, as well as its lowvoltage ride-through (LVRT) capacity [5], [6].

\section{Detailed model of a wind farm}

To represent the wind farm behaviour, first, its detailed model has been developed according to widely used PMSG wind turbine models in literature such as [7], [8].

Fig. 1 shows a typical configuration of a PMSG wind turbine.

\section{A. Rotor model}

The mechanical power extracted from the wind can be expressed as follows [7],

$$
P_{W}=\frac{1}{2} \cdot \rho \cdot \pi \cdot R^{2} \cdot C_{P}(\lambda, \theta) \cdot V_{W}^{3}
$$

where $P_{W}$ is the mechanical power extracted by the wind turbine rotor, $\rho$ is the air density, $R$ is the turbine rotor 
radius, $C_{P}$ is the power coefficient and $V_{W}$ is the wind speed.

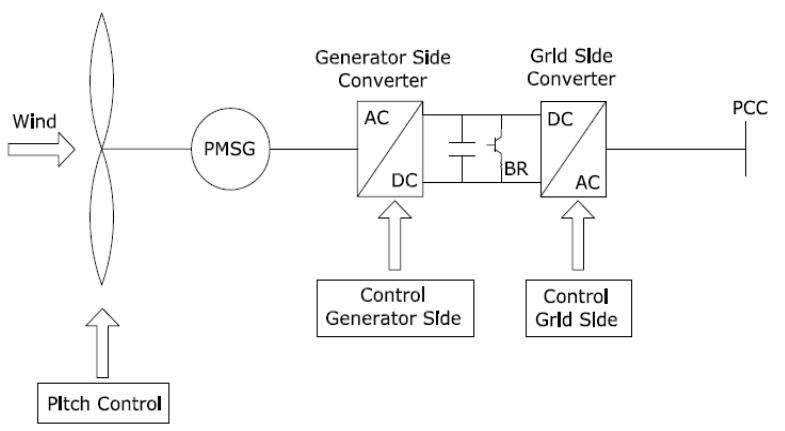

Fig. 1. Block diagram of the wind turbine based on PMSG

$C_{P}$ is a measurement of how efficiently the wind turbine converts the wind energy into the turbine mechanical energy, and it is a function of the tip speed ratio, $\lambda$, and the blade pitch angle, $\theta$.

The tip speed ratio is defined as follows,

$$
\lambda=\frac{W_{r} \cdot R}{V_{W}}
$$

where $W_{r}$ is the rotor angular speed.

It can be concluded that when the pitch angle is equal to zero, the power coefficient attains its maximum value for an optimal tip speed ratio and so, the power extracted from the wind is maximized [8].

From (1) it can be derived that the mechanical torque is,

$$
T_{m}=\frac{1}{2} \cdot \rho \cdot \pi \cdot R^{5} \cdot C_{P}(\lambda, \theta) \cdot \frac{W_{r}^{2}}{\lambda^{3}} .
$$

\section{B. Drive train model}

The mechanical power is transfered to the generator through the drive train. In a direct-drive PMSG wind turbine, a gearbox is not needed, because a multipole generator allows it to operate at low speeds, therefore the generator is directly coupled to the wind turbine rotor.

The drive train is represented by the one-mass model, where all rotating masses (hub, blades and rotor of generator) are represented by one element. This model is defined by the following equation,

$$
T_{m}-T_{e}=J_{e q} \cdot \frac{d W_{r}}{d t}
$$

where $T_{m}$ is the mechanical torque, $T_{e}$ is the electrical torque and $J_{e q}$ is the equivalent inertia of the rotating system.

\section{Permanent magnet synchronous generator model}

The dynamic model of the PMSG has been built in the d-q reference frame rotating at electrical speed with the position of the direct axis aligned along the permanent magnet flux position.
The stator voltage equations in $\mathrm{d}-\mathrm{q}$ reference frame have the following form [7],

$$
\begin{gathered}
u_{s d}=-R_{s} \cdot i_{s d}-L_{s d} \cdot \frac{d i_{s d}}{d t}+W_{e} \cdot L_{s q} \cdot i_{s q} \\
u_{s q}=-R_{s} \cdot i_{s q}-L_{s q} \cdot \frac{d i_{s q}}{d t}+W_{e} \cdot\left(\psi_{m}-L_{s d} \cdot i_{s d}\right)
\end{gathered}
$$

where $u_{s d}, u_{s q}$ are the generator voltages, $i_{s d}, i_{s q}$, are the generator currents, $R_{s}$ is the stator winding resistance, $L_{s d}$, $L_{s q}$ are the stator inductances, $\Psi_{m}$ is the magnet flux and $W_{e}$ is the generator angular speed.

As the PMSG uses a surface magnet generator, the inductances in $\mathrm{d}-\mathrm{q}$ reference frame are identical and the electromagnetic torque can be expressed as [7],

$$
T_{e}=\frac{3}{2} \cdot p_{p} \cdot \psi_{m} \cdot i_{q}
$$

where $p_{p}$ is the number of pole pairs.

\section{Power converter model}

The PMSG is directly connected to the grid through a back-to-back (B2B) converter. It consists of two identical voltage source converters and a capacitor which is connected between them. As the power losses are ignored, the dynamic behaviour of the DC-link can be expressed by the following equation,

$$
\frac{d u_{d c}}{d t}=\frac{1}{C} \cdot\left(I_{d c-R}-I_{d c-I}\right)
$$

where $u_{d c}$ is the DC-link voltage, $C$ is the value of the DClink capacitor, $I_{d c-R}$ is the rectifier current and $I_{d c-I}$ is the inverter current.

The generator-side converter, which acts as a rectifier, converts the generator's low AC frequency to DC. The DC voltage is stabilized by the DC-link capacitor and converted further by the grid-side converter into $50 \mathrm{~Hz}$ AC, which is supplied to the grid.

A full scale power converter decouples the generator from the grid and allows full controllability of the system.

\section{E. Protection system model}

When a voltage dip occurs at the AC output terminals of the wind turbine, the maximum active power that the wind turbine can export to the grid is reduced in proportion to the terminal voltage reduction. An energy imbalance appears in the wind turbine compared to its operation at undisturbed terminal voltage because the output power is quickly reduced by the inverter controller while the input power extracted from the wind cannot be reduced as quickly. When the LVRT capability of the wind turbine is analyzed, it is clearly seen that the impact of the energy imbalance is significant.

As proposed in [6], instead of storing the excess energy in the DC-link, a resistor is inserted in the DC circuit to dissipate the excess energy and restore the balance. This braking resistor balances output torque variations and 
prevents the DC-link voltage from rising excessively. The resistor is controlled using a power electronic switch, as Fig. 2 shows.

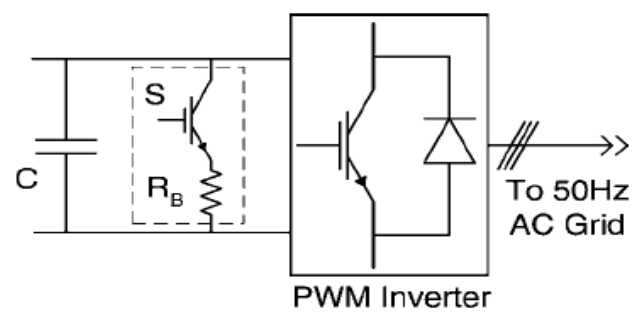

Fig. 2. Braking resistor scheme [6]

\section{F. Grid model}

The dynamic model of the grid connection when selecting a reference frame rotating synchronously with the grid voltage space vector is the following [7],

$$
\begin{aligned}
& u_{g d}=u_{c d}-R_{g} \cdot i_{g d}-L_{g d} \cdot \frac{d i_{g d}}{d t}+W_{g} \cdot L_{g q} \cdot i_{g q} \\
& u_{g q}=u_{c q}-R_{g} \cdot i_{g q}-L_{g q} \cdot \frac{d i_{g q}}{d t}-W_{g} \cdot L_{g d} \cdot i_{g d}
\end{aligned}
$$

where $u_{g d}, u_{g q}$ are the grid voltages, $u_{c d}, u_{c q}$ are the voltage components of grid side converter, $i_{g d}, i_{g q}$, are the grid currents, $R_{g}$ is the grid resistence, $L_{g d}, L_{g q}$ are the grid inductances and $W_{g}$ is the grid frequency.

As the $d$-axis of the reference frame is oriented along the grid voltage $\left(\vec{u}_{g}=u_{g d}+j \cdot 0.\right)$, the active and reactive powers can be expressed as,

$$
\begin{gathered}
P_{g}=\frac{3}{2} \cdot u_{g d} \cdot i_{g d} \\
Q_{g}=\frac{3}{2} \cdot\left(-u_{g d} \cdot i_{g q}\right) .
\end{gathered}
$$

From (11) and (12), it can be deduced that the active and reactive power control can be achieved by controlling the direct and quadrature current components, respectively [8].

\section{Control system}

\section{A. Control strategies}

The aim of the generator-side converter controller is to work at the rotor speed that extracts the maximum power from the wind without exceeding the wind turbine working limits.

To achieve this objective, the control system is structured in a nested-loop consisting of an inner loop to control the stator currents, and an outer loop to control the rotor speed or the active power depending on the control strategy selected.

In both control strategies, the required d-q components of the voltage vector are derived from two PI current controllers; after the PI, compensation terms are added to improve the dynamic response.

The $d$-axis current reference is kept at zero because, as equation (7) shows, the generator torque may be controlled directly by the $q$-axis current component [7]. In that way, the torque will be obtained by using the minimum value of the stator current amplitude.

In control strategy I, the $q$-axis current reference is obtained from the rotor speed controller as shown in Fig. 3 , and the rotor speed reference is obtained from equation (2).
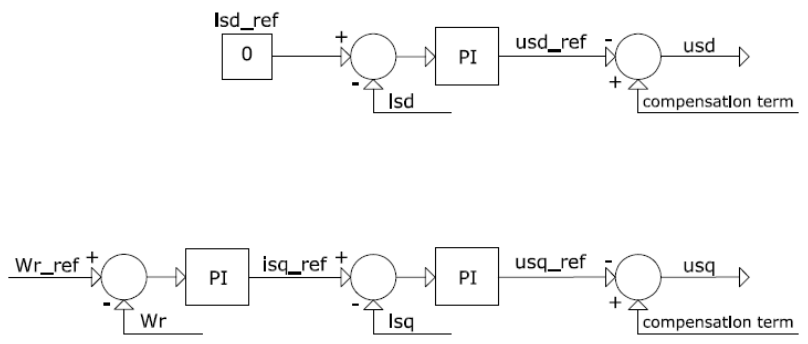

Fig. 3. Generator side converter control scheme Control strategy I

In control strategy II, the $q$-axis current reference is obtained from the active power controller as shown in Fig. 4 , and the active power reference is obtained from the following equation [8],

$$
P_{e_{-} r e f}=K_{o p t} \cdot W_{r}^{3}
$$

where,

$$
K_{o p t}=\frac{1}{2} \cdot \rho \cdot \pi \cdot R^{5} \cdot \frac{C_{p_{-} \max }}{\lambda_{o p t}^{3}} .
$$

On the other hand, the objectives of the grid-side converter controller are to keep the DC-link voltage constant and to control the reactive power delivered to the grid. To achieve these objectives, the control system is also structured in a nested-loop, as shown in Fig. 5. The inner loop controls the grid currents and the outer one controls the DC-link voltage. The $q$-axis grid current is kept at zero in order to maintain the reactive power equal to zero.
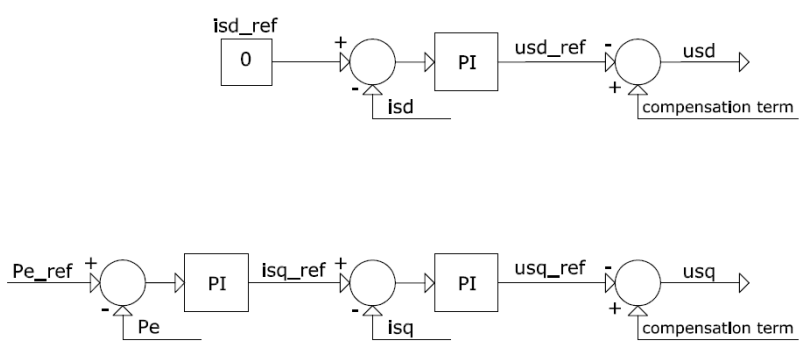

Fig. 4. Generator-side converter control scheme Control strategy II 


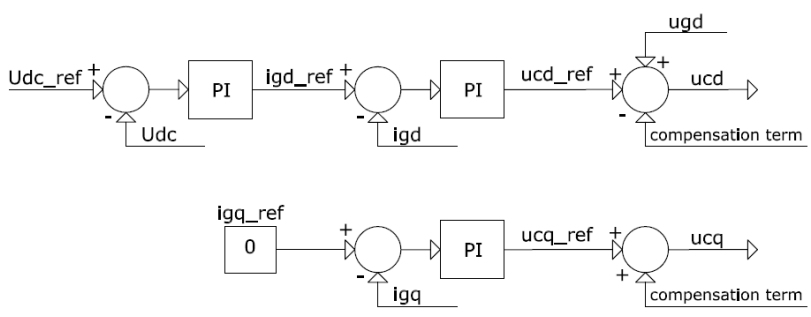

Fig. 5. Grid-side converter control scheme

\section{B. Pitch angle control system}

The pitch angle controller is only active in high wind speeds. It prevents the rotor speed or the generator active power, depending on the control strategy used, from becoming too high, changing the blade pitch in order to reduce $C p$ and therefore the power extracted from the wind.

In control strategy I, the pitch angle controller maintains the optimal pitch angle when the generator active power is less than the rated power. When the power is above the rated value, this controller limits the generator active power to the rated value.

In control strategy II, the pitch angle controller maintains the optimal pitch angle when the rotor speed is less than the rated speed. When the rotor speed is above the rated value, this controller limits the rotational speed to the rated value.

\section{Aggregate model of wind farms}

An equivalent model of a wind farm with PMSG wind turbines is proposed in this paper. The model is based on aggregating wind turbines into an equivalent wind turbine considering the following aspects:

-Re-scaled power capacity, which means that its rated power is equal to $n$ times the rated power of the individual one, where $n$ is the number of aggregated wind turbines.

-The aggregated wind turbine is represented by an equivalent mechanical torque which is $n$ times the rated mechanical torque of the individual wind turbines.

$$
T_{m-e q}=\sum_{i=1}^{n} T_{m i}
$$

-The inertia of the aggregated wind turbine is also $n$ times the inertia of the individual wind turbines.

$$
J_{e q}^{\prime}=n \cdot J_{e q} \cdot
$$

-The aggregated wind turbine is connected to an equivalent PMSG, which its dynamic model is the same as the individual generator model, given by the equations (5)-(6), with the stator impedance $n$ times smaller.

-The B2B converter is considered ideal and the DC-link voltage between the two voltage source converters is constant. The dynamic behaviour of the DC-link can be expressed by (8), with a redefined capacitor,

$$
C_{e q}=n \cdot C .
$$

-The aggregated grid connection dynamic model is also represented by the individual model, given by equations (9)-(10), with the grid impedance $n$ times smaller.

\section{Simulation results}

The wind farm modeled in this paper contains $3 \times 5 \mathrm{MW}$ surface-mounted PMSG wind turbines connected to the grid, as shown in Fig. 6. The simulation study compares the detailed and equivalent models of the wind farm taking into account the different generator-side converter control strategies used in this paper, when a wind step from $11.70 \mathrm{~m} / \mathrm{s}$ to $15 \mathrm{~m} / \mathrm{s}$ at $1 \mathrm{~s}$ is applied to the system.

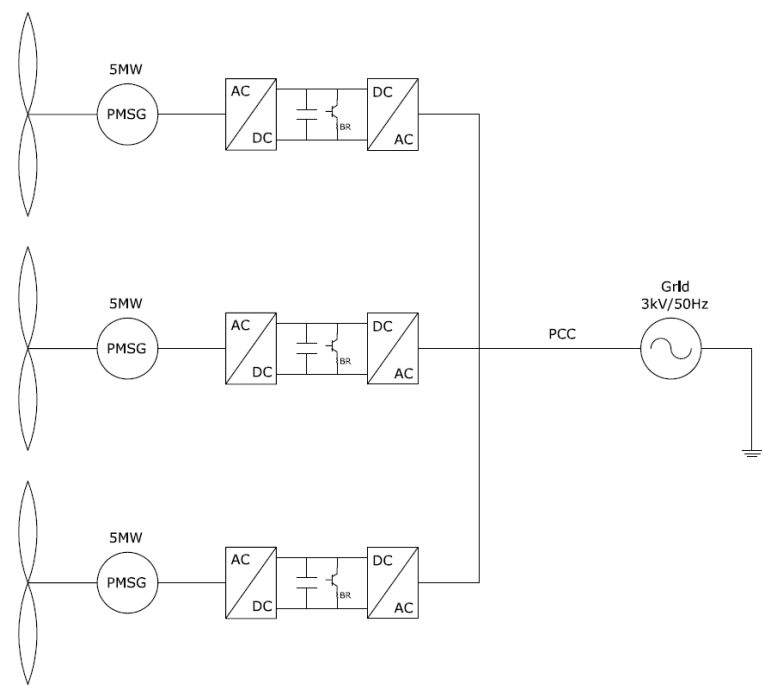

Fig. 6. Simulation system

\section{A. Control strategy I}

In control strategy I, when wind speed changes the mechanical torque increases rapidly, as shown in Fig. 7. The electrical torque also increases but up to a certain limit due to generator currents design restrictions, then there is a torque imbalance and the rotor accelerates. When the active power is overrated, the pitch controller changes the blade pitch in order to reduce $C p$ and therefore the mechanical torque, to restore the energy balance.

In addition, input and output power of the B2B converter must be equal, so the changes in the generator power are also transmitted into the grid, as shown in Fig. 8.

Fig. 9 shows how the DC-link voltage increases in order to keep the energy balance in the power converter.

\section{B. Control strategy II}

In control strategy II, when wind speed changes the mechanical torque increases rapidly, as shown in Fig. 10. As the power extracted by the generator from the air kinetic energy is limited to the rated value, due to the design restrictions, the wind turbine rotor accelerates much more than in control strategy I. When rotor speed is 
overrated, the pitch controller changes the blade pitch in order to reduce $C p$ and therefore the mechanical torque, to restore the energy balance.

If Fig. 7 and 10 are compared, it is clearly seen that in control strategy II, the wind turbine system takes more time to restore the steady-state than in control strategy I. Although it seems a disadvantage, actually this behaviour is smoother so better for the wind turbines' components.

As mentioned before, input and output powers of the B2B converter must be equal, so generator power is transmitted into the grid, as shown in Fig. 11. In this case, there is not an energy imbalance in the power converter and so the DC-link voltage remains constant, as shown in Fig. 12.

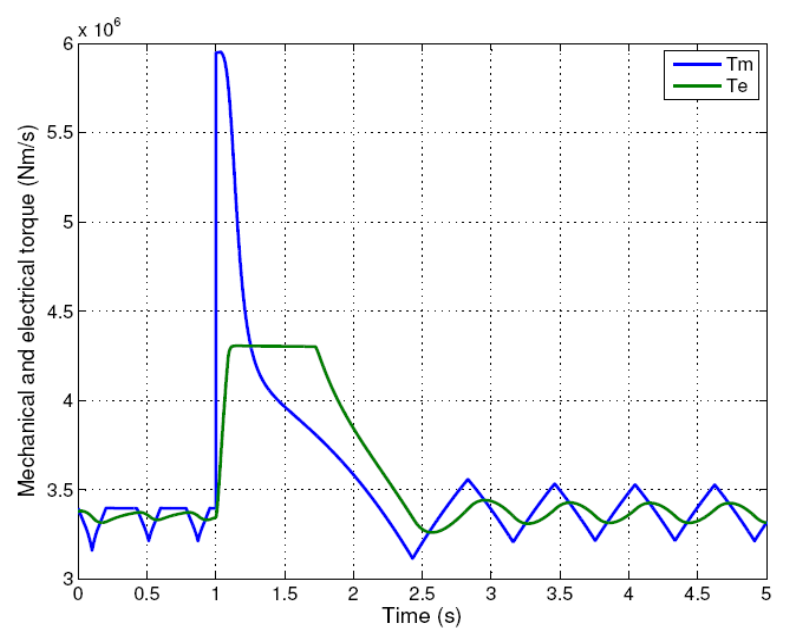

Fig. 7. Mechanical and electrical torques. Control strategy I

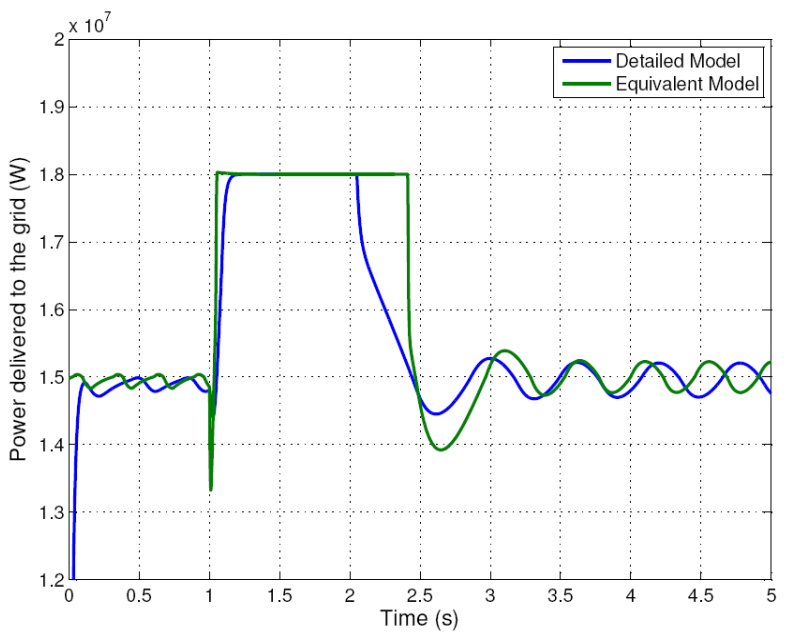

Fig. 8. Active power delivered to the grid. Control strategy I

\section{LVRT capability}

The LVRT capability of the wind farm is considered. The wind speed is given as a constant of $11.70 \mathrm{~m} / \mathrm{s}$.

A voltage dip at point of common coupling (PCC) is simulated with a reduction of an $80 \%$ of rated value during 1 second. Note that the maximum power delivered to the grid is directly related to the terminal voltage reduction, as shown in Fig. 13. Without protection, there would be an energy imbalance between the generator power and the grid power that would result in an undesirable high value of the DC-link voltage. However, the braking resistor controls the power dissipation and the energy balance in the system is restored, as Fig. 14 shows.

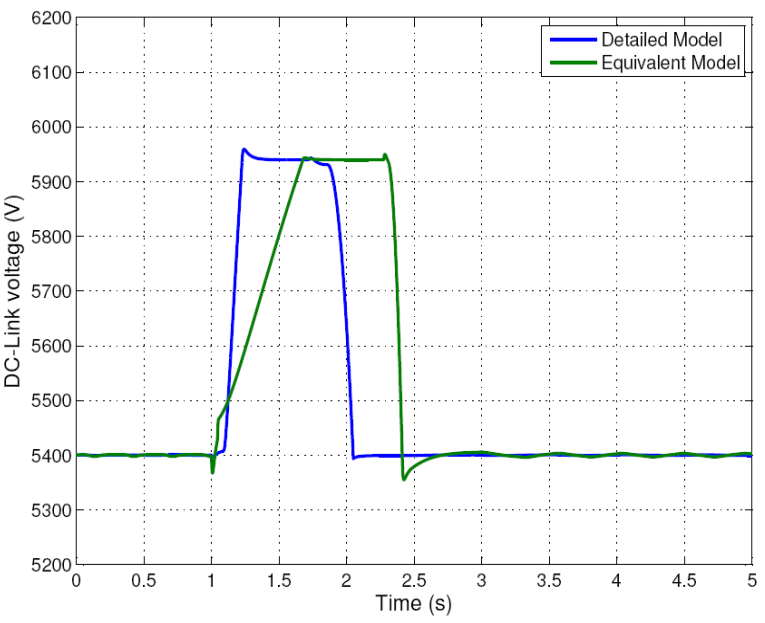

Fig. 9. DC-link voltage. Control strategy I

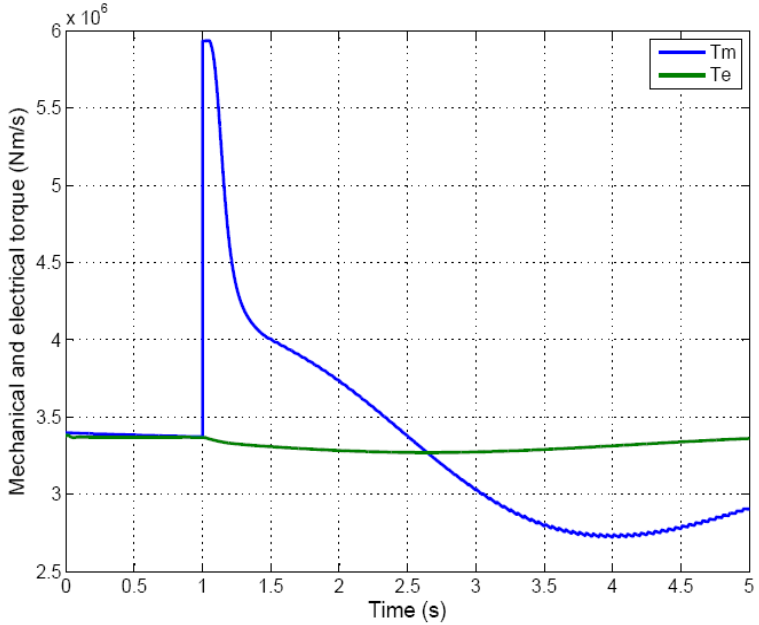

Fig. 10. Mechanical and electrical torques. Control strategy II

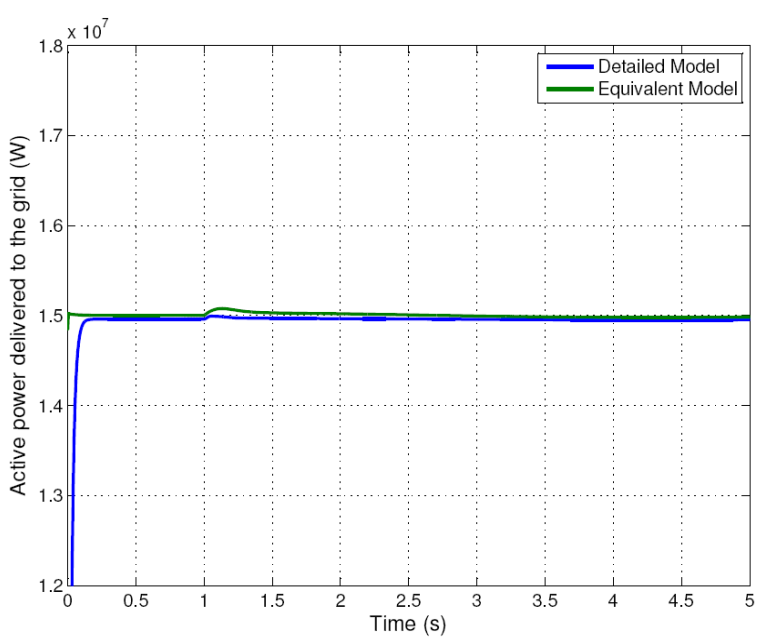

Fig. 11. Active power delivered to the grid. Control strategy II 
As deduced from all figures shown, the aggregated model follows closely the detailed one in all the cases studied, regardless of the control strategy used.

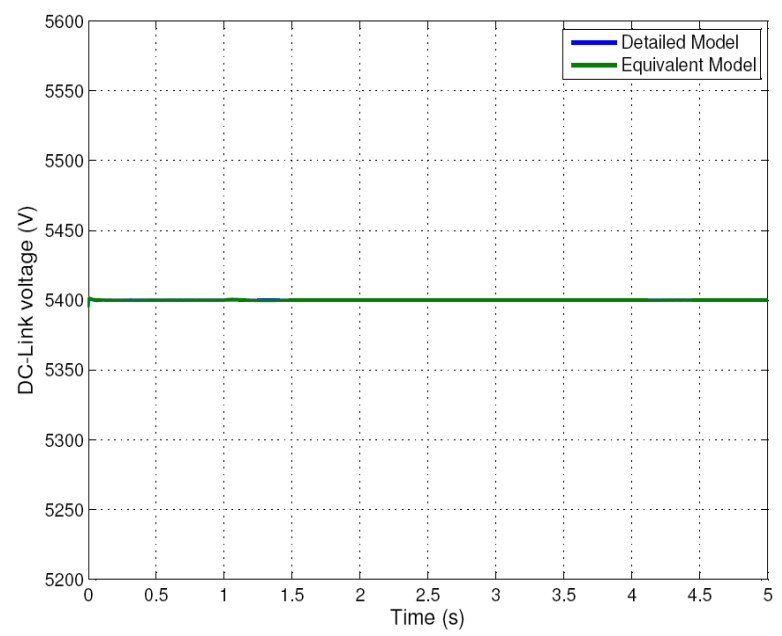

Fig. 12. DC-link voltage. Control strategy II

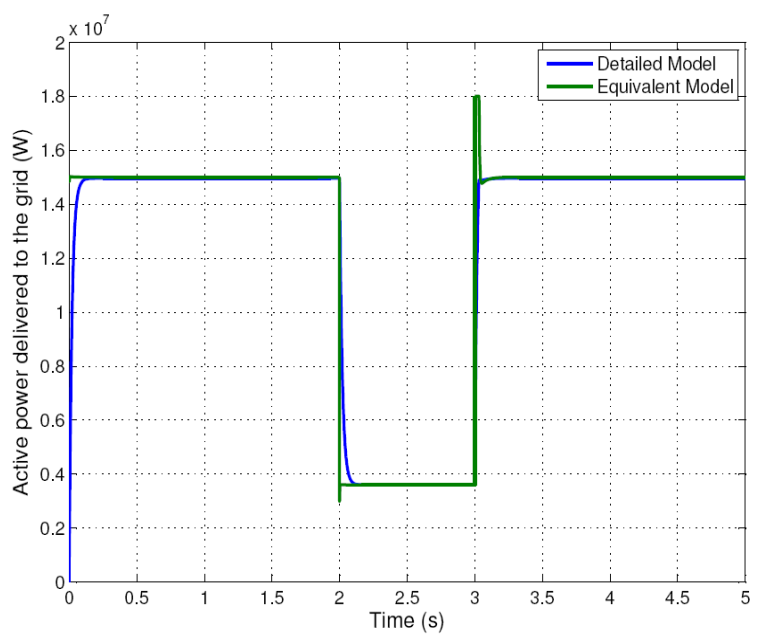

Fig. 13. Active power delivered to the grid

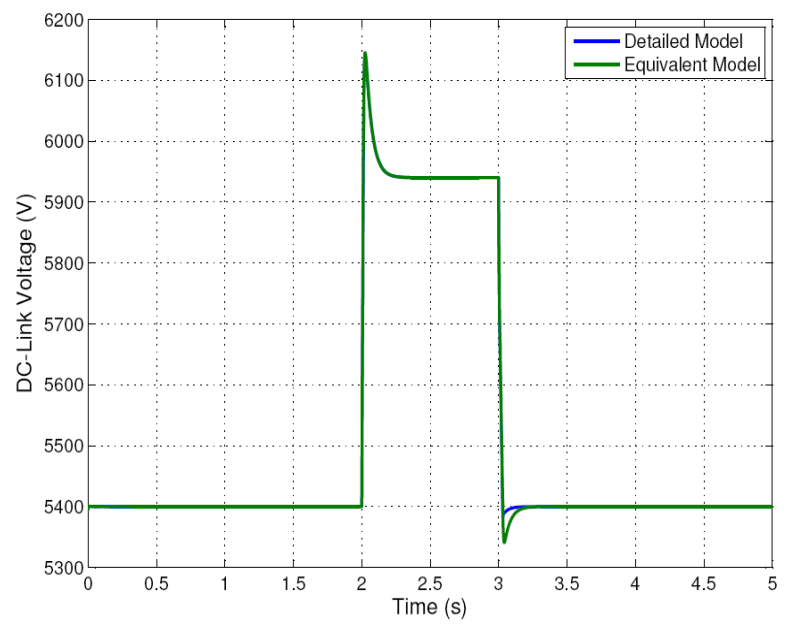

Fig. 14. DC-link voltage

\section{Conclusions}

This paper illustrates the behaviour of an aggregated model with PMSG wind turbines, under two control strategies, when a wind fluctuation or a grid disturbance happens.

In control strategy I, the generator-side converter controls the rotor speed; while, in control strategy II, it controls the generator active power. When the wind speed changes rapidly, the simulation results show that the power control is a better control strategy because, although the wind turbine system takes longer to reach again the steady-state, its behaviour is smoother and therefore, the wind turbines' components are less stressed.

When a voltage dip occurs at PCC, the simulation results show that the LVRT capability of the wind farm is good enough due to the braking resistor action.

Finally, the proposed aggregated model behaviour follows closely the detailed one in all the cases studied. Therefore, the proposed equivalent model is a good way to represent the wind farm behaviour, reducing calculation time without losing information.

\section{References}

[1] Akhmatov, V.; Knudsen, H. 'An aggregated model of a gridconnected, large-scale, offshore wind farm for power stability investigations- importance of windmill mechanical system'. Electrical power and energy systems, No. 24, pp. 709-717, 2002.

[2] Fernández, L.M. et al. 'Aggregated dynamic model for wind farms with doubly fed induction generator wind turbines'. Renewable Energy, No. 33, pp. 129-140, 2008.

[3] Li, H.; Chen, Z. 'Overview of different wind generator systems and their comparisons'. IET Renewable Power Generation, Vol. 2, No. 2, pp. 123-138, 2008.

[4] Conroy, J; Watson, R. 'Aggregate modelling of wind farms containing full-converter wind turbine generators with permanent magnet synchronous machines: transient stability studies'. IET Renewable Power Generation, Vol. 3, No. 1, pp. 39-52, 2009.

[5] Deng, F.; Chen, Z. 'Low-voltage ride-through of variable speed wind turbines with permanent magnet synchronous generator'. IECON Proceedings. 2009.

[6] Conroy, J. F.; Watson, R. 'Low-voltage ride-through of a full converter wind turbine with permanent magnet generator'. IET Renewable Power Generation, Vol. 1, No. 3, pp. 182-189, 2007.

[7] Chinchilla, M.; Arnaltes, S.; Burgos, J. C. 'Control of permanent-magnet generators applied to variable-speed windenergy systems connected to the grid'. IEEE Transactions on energy conversion, Vol. 21, No. 1, pp. 130-135, 2006.

[8] Fernández, L.M. et al. 'Operating capability as PQ/PV node of a direct-drive wind turbine based on a permanent magnet synchronous generator'. Renewable Energy, No. 35, pp. 13081318, 2010. 